\title{
Predominant role for C5b-9 in renal ischemia/reperfusion injury
}

\author{
Wuding Zhou, ${ }^{1}$ Conrad A. Farrar, ${ }^{1}$ Katsushige Abe, ${ }^{1}$ Julian R. Pratt, ${ }^{1}$ \\ James E. Marsh, ${ }^{1}$ Yi Wang, ${ }^{2}$ Gregory L. Stahl, ${ }^{3}$ and Steven H. Sacks ${ }^{1}$
}

${ }^{1}$ Department of Nephrology and Transplantation, Guy's Hospital, London, United Kingdom

${ }^{2}$ Alexion Pharmaceuticals, New Haven, Connecticut, USA

${ }^{3}$ Center for Experimental Therapeutics and Reperfusion Injury, Department of Anesthesia, Brigham and Women's Hospital, Harvard Medical School, Boston, Massachusetts, USA

Address correspondence to: Steven H. Sacks, Department of Nephrology and Transplantation, 5th Floor, Thomas Guy House, Guy's Hospital, King's College London, St. Thomas Street, London SE1 9RT, United Kingdom. Phone: 44-171-955-4305;

Fax: 44-171-955-4303; E-mail: steven.sacks@kcl.ac.uk.

Received for publication October 6, 1999, and accepted in revised form March 28, 2000.

Previous work has indicated that complement is a mediator of ischemia/reperfusion (I/R) injury. To investigate the components of complement responsible for this effect, we examined a model of renal I/R injury in C3-, C4-, C5-, and C6-deficient mice. We occluded the renal arteries and veins (40-58 minutes) and, after reperfusion (0-72 hours), assessed renal structural and functional injury. C3-, C5-, and C6-deficient mice were protected from renal I/R injury, whereas C4-deficient mice were not protected. C6-deficient mice treated with antibody to block C5a generation showed no additional protection from I/R injury. Reconstitution with $\mathrm{C} 6$ alone restored the I/R injury in C6-deficient mice. Tubular epithelial cells were the main structures damaged by complement-mediated attack, and, in contrast, the renal vessels were spared. Neutrophil infiltration and myeloperoxidase activity were reduced in Cdeficient mouse kidney, but by a similar extent in C3-deficient and C6-deficient mice. We conclude that the membrane attack complex of complement (in which $\mathrm{C} 5$ and $\mathrm{C} 6$ participate) may account for the effect of complement on mouse renal I/R injury. Neither C5a-mediated neutrophil infiltration nor the classic pathway, in which $\mathrm{C} 4$ participates, appears to contribute to I/R injury in this model. By contrast with other organs, such as the heart, the primary effect of complement in the ischemic area is on the parenchymal cell rather than the vascular endothelial cell. The membrane attack complex of complement is a potential target for prevention of $\mathrm{I} / \mathrm{R}$ injury in this model.

J. Clin. Invest. 105:1363-1371 (2000).

\section{Introduction}

Ischemia reperfusion (I/R) injury occurs when blood flow is restored after an extended period of ischemia (1). It is a common source of morbidity and mortality in conditions such as myocardial infarction, stroke, gut ischemia, and cardiopulmonary bypass; for which there is often no specific therapy. Renal I/R damage is a feature of acute hypovolemic renal failure $(2,3)$ and has a major impact on short- and long-term graft survival after organ transplantation $(4,5)$.

The pathophysiology of I/R injury is complex, with at least three major components contributing to the process of reperfusion injury: molecular oxygen, neutrophils, and components of the activated complement (C) cascade (6-8). More recent studies have recognized the importance of factors produced by activated endothelium in I/R injury, such as adhesion molecules, cytokines, platelet-activating factors, leukotrienes, Pselectin, and endothelin (9-12). Although the generation of oxygen-derived free radicals and neutrophil activation are most noteworthy, $\mathrm{C}$ activation is an early event in the course of reperfusion injury. The generation of $\mathrm{C}$ effector molecules may influence the function of other factors, such as free radicals, neutrophils, and the products of activated endothelium (8). C activation releases a number of biologically active products, several of which possess proinflammatory activity in vitro. The early products $\mathrm{C} 4 \mathrm{a}, \mathrm{C} 3 \mathrm{a}$, and $\mathrm{C} 5 \mathrm{a}$, the anaphylatoxins, can induce smooth muscle contraction, increase vascular permeability, and cause the release of histamine $(13,14)$. In addition, C5a can act directly on neutrophils, promoting chemotaxis and activation (13), and can act on both neutrophils and endothelium to upregulate cell adhesion molecules such as CD11b/CD18 and intercellular adhesion molecule (ICAM-1) $(15,16)$. The membrane attack complex (MAC), C5b-9, inserts into the membrane of target cells, directly inducing cell injury and necrosis (17). Sublethal amounts of C5b-9 can activate neutrophils and endothelium by upregulating adhesion molecules and promoting the release of cell stimulants such as hydrolytic enzymes, reactive oxygen species, arachidonic acid metabolites, and cytokines (18-21). In addition, C5b-9 can enhance the procoagulant properties of endothelium (22).

The role of $\mathrm{C}$ in I/R injury has been studied in a number of organs such as heart, lung, brain, intestine, and muscle. Weisman et al. demonstrated that $\mathrm{C}$ inhibition with soluble $\mathrm{C}$ receptor type 1 (sCR1), administered 
before coronary occlusion, reduced myocardial infarct size after reperfusion in rats (23). Using cobra venom factor (CVF) to deplete $\mathrm{C}$ in rats, Ikai et al. showed that systemic shock was reduced in intestinal I/R (24), and Eppinger et al. showed that lung $\mathrm{I} / \mathrm{R}$ injury was reduced in rats (25). Weiser et al. found that hind limb I/R injury was reduced in C-deficient (def) mice (26). These studies suggest that $\mathrm{C}$ play an important pathogenic role in $\mathrm{I} / \mathrm{R}$ injury. However, much less is known about the relative importance of the early (C4a, C3a), intermediate (C5a), and late (C5b-9) products of $\mathrm{C}$ activation in the generation of $\mathrm{I} / \mathrm{R}$ injury. This is important because by understanding the means by which $C$ participates in the pathogenesis of $\mathrm{I} / \mathrm{R}$ injury, one can be more precise about targets for therapy. In renal $I / R$ injury, little is known about the role of C.

The renal tubule is one of the main targets damaged in renal I/R injury, with important functional consequences on the regulation of urine volume and composition. The tubular epithelial cell may actively contribute to the process of injury, given that when stimulated by inflammatory mediators such as complement, proximal tubule cells in culture release profibrotic growth factors, cytokines, and matrix proteins (27-30). A key question about the potential role of $\mathrm{C}$ in reperfusion injury is whether it acts predominantly on the parenchymal cell or on the endothelial cell of vessels delivering blood to the ischemic area or whether it acts mainly by recruiting inflammatory cells into the damaged area. Endothelial- and neutrophil-mediated damage has been suggested as a predominant mechanism by myocardial reperfusion studies (31).

We set out primarily to dissect the contribution of specific complement components in renal I/R injury, namely C3, C4, C5, and C6. A secondary objective was to characterize more fully the tissue segment targeted by the complement attack.

\section{Methods}

Animals. Homozygous C3- and C4-def mice were derived by homologous recombination in embryonic stem cells as described previously $(32,33)$. Because C3and C4-def mice were produced in C57/BL6 (B6) with 129 strain embryonic stem cells, we used B6x129 F2 littermates as wild-type (WT) controls for most experiments. We also performed experiments (when indicated) with B6 C3-def mice that were backcrossed onto the B6 parental strain for eight generations, once these were available. Backcrossed-to-B6 skin grafts were accepted indefinitely (>100 days). C5-def mice have a spontaneous mutation of their complement component. C5-def (B10.D2.osn) and C5-sufficient (suf; B10D2.nsn) mice were purchased from The Jackson Laboratories (Bar Harbor, Maine, USA). C6-def mice were derived from a Peruvian strain backcrossed with $\mathrm{C} 3 \mathrm{H} / \mathrm{He}$ mice for ten generations. These $\mathrm{C} 3 \mathrm{H} / \mathrm{He}$ C6def mice were provided by P. Lachmann (Cambridge, United Kingdom) (34), and the $\mathrm{C} 3 \mathrm{H} / \mathrm{He}$ (WT) mice were purchased from Harlan UK Ltd. (Bicester, United
Kingdom). All C-def mice had no plasma activity of their respective $\mathrm{C}$ components. Eight-week-old male mice were used throughout the experiments.

Ischemia protocol. Mice (25-30 g) were anesthetized by inhalation of Enflurane (Abbott Laboratories Ltd., Kent, United Kingdom) and by intraperitoneal administration of Hypnovel $(6.64 \mathrm{mg} / \mathrm{kg}$; Roche Products Ltd., Welwyn Garden City, United Kingdom), to reduce the usage of Enflurane. We preferred this form of anesthesia, as it proved less toxic than barbiturate and allowed more reproducible I/R injury. Body temperature was kept constant by placing a warm pad beneath the animal. Using a midline abdominal incision, renal arteries and veins were bilaterally occluded for 58 minutes (except C5-def and C5-suf mice, which had their vessels occluded for 40 minutes) with microaneurysm clamps (Codman, Berkshire, United Kingdom). This period of ischemia was predetermined (for this anesthetic protocol) using a range of occlusion times of 30-62 minutes and found to give reversible injury. After occlusion, 0.8 $\mathrm{mL}$ of prewarmed $\left(37^{\circ} \mathrm{C}\right)$ saline was placed in the abdominal cavity and the abdomen was closed. After removal of the clamps, the kidneys were observed for an additional 1 minute to see the color change indicative of blood reflow. After suturing, the incision mice were returned to their cages. Sham-treated mice had identical surgical procedures except that microaneurysm clamps were not applied. Tail blood samples were taken at 6,24 , and 48 hours of reperfusion. Mice were sacrificed at 72 hours; blood samples were collected by cardiac puncture; and kidneys were harvested for assessment of renal injury. Additional, identically treated groups of mice were also sacrificed at 2, 6, 24, and 48 hours of reperfusion. Harvested kidney samples were used for histological examination and immunochemical staining. Although in previous studies of renal I/R injury in mice, an ischemia of 30-32 minutes was applied $(9,35)$, we found that under our anesthesia conditions, for most strains of mice, 58 minutes of ischemia was optimal to reproduce functional impairment while avoiding the no-reflow phenomenon. In total, 375 mice were evaluated in this study.

Assessment of renal function. Blood urea nitrogen (BUN) was measured by coupled enzyme reactions involving urease and glutamate dehydrogenase using a Sigma Kit (BUN [Rat]; Sigma-Aldrich Co., Dorset, United Kingdom). Serum creatinine was measured by HPLC and performed by hospital research services. We achieved reproducible correlation between the two assays, and therefore creatinine data are not shown.

Assessment of renal morphological changes. After surgical removal from mice, kidneys were cut coronally, fixed in $4 \%$ paraformaldehyde and embedded in paraffin. Sections $(2 \mu \mathrm{m})$ were stained with periodic acid-silver nitrate (PAS) and reviewed in a blinded fashion by two persons. One whole deep coronal section was examined under a microscope. The percentage of tubules damaged in the corticomedullary junction was estimated using a five-point scale (9) as follows: 0, normal kidney; 
1 , less than $10 \%$ necrosis; 2 , $10-25 \%$ necrosis; 3 , 25-75\% necrosis; and 4, more than $75 \%$ necrosis. Martius scarlet and blue (MSB) staining, a method highly selective for fibrin, was performed to detect thrombosis (36).

Myeloperoxidase activity. Myeloperoxidase (MPO) activity, used as an indicator of neutrophil infiltration, was assayed in supernatants of kidney homogenates as described previously (37). Briefly, kidney tissue (quarter-kidney) was homogenized in $5 \mathrm{mM}$ potassium phosphate buffer ( $\mathrm{pH}$ 6.0). Homogenates were centrifuged at $30,000 \mathrm{~g}$ for 30 minutes at $4^{\circ} \mathrm{C}$. The pellets were resuspended in $1 \mathrm{~mL}$ of extraction buffer $(50 \mathrm{mM}$ potassium phosphate buffer [ $\mathrm{pH} 6.0$ ] containing $0.5 \%$ hexadecyl trimethylammonium bromide [HTAB]) and followed by three rounds of freeze/thawing. Supernatants were generated by clarification at $13,000 \mathrm{~g}$ for 15 minutes at $4^{\circ} \mathrm{C}$. Sample protein concentrations were determined using a Micro BCA Protein Assay Reagent Kit (Pierce Chemical Co., Rockford, Illinois, USA), using BSA for the standard curve. MPO was assayed by a microtiter plate method. Briefly, $100 \mu \mathrm{L}$ of sample was mixed with $100 \mu \mathrm{L}$ of reaction buffer (50 $\mathrm{mM}$ potassium phosphate buffer [ $\mathrm{pH} 6.0]$, containing $0.167 \mathrm{mg} / \mathrm{mL}$ of 0 -dianisidine dihydrochloride, and $0.0006 \% \mathrm{H}_{2} \mathrm{O}_{2}$ ). Absorbance was measured at $460 \mathrm{~nm}$ using a microplate reader. MPO content was expressed as units of MPO activity per milligram of protein.

Immunochemical staining. Frozen sections $(4 \mu \mathrm{m})$ were cut and fixed with acetone and then stained using an indirect method. The following antibodies were used: for neutrophil staining, rat anti-mouse neutrophil (Serotec Ltd., Oxford, United Kingdom) and horseradish peroxidase-conjugated (HRP-conjugated) goat anti-rat IgG; for C3 staining, rabbit anti-human C3d (Dako Ltd., Cambridge, United Kingdom) and HRPconjugated goat anti-rabbit IgG.

Inbibition of terminal $C$ pathway activity. Monoclonal anti-mouse C5 (BB5.1) and the isotype-matched control antibody 135.8 were used in this study (38). Antibodies $(50 \mathrm{mg} / \mathrm{kg})$ were administered intraperitoneally 16 hours before the induction of renal ischemia.

Reconstitution of C6 in C6-def mice. Human C6 was purified from a monoclonal affinity column and stored in PBS. Coomassie blue staining of this preparation run on an SDS-PAGE gel showed that the majority of it was in a single band at the appropriate molecular size (120 $\mathrm{kDa})$. The dose $(75 \mu \mathrm{g}$ per mouse) was chosen based on an assumption of correcting the serum compartment to about $55 \mu \mathrm{g} / \mathrm{mL}$ (39).

Mouse serum $C$ activity assay. This assay was used to examine the activity of $\mathrm{C}$ in mouse serum after treatment with anti-C5 antibody. Blood samples were collected by cardiac puncture and stored at $-70^{\circ} \mathrm{C}$. The functional activity of the alternative pathway of $\mathrm{C}$ was assessed by a hemolytic $\mathrm{C}$ assay according to the method described by Klerx et al. (40). Briefly, $50 \mu \mathrm{L}$ of rabbit erythrocytes (Harlan Sera-Lab Ltd., Loughborough, United Kingdom) were suspended in $100 \mu \mathrm{L}$ of veronal buffered saline at a concentration of $1 \times$
$10^{8} / \mathrm{mL}$ and then incubated in a 96-well plate with serial dilutions of mouse serum and zymosan (SigmaAldrich Co.) for 1 hour at $39^{\circ} \mathrm{C}$. The plate was centrifuged for 10 minutes, and then supernatants were collected and transferred to a new 96-well plate. Absorbance was measured at $405 \mathrm{~nm}$ using a microplate reader, and the percentage hemolysis at each serum concentration was determined according to the following formula:

(equation 1)

$\%$ Hemolysis $=\frac{\mathrm{OD}_{405}(\text { test sample })-\mathrm{OD}_{405}(\text { heat-inactivated sample })}{\mathrm{OD}_{405}(100 \% \text { hemolysis })-\mathrm{OD}_{405}(0 \% \text { hemolysis })} \times 100$

One hundred percent hemolysis was obtained by exposing the red cells to water instead of veronal buffered saline, and $0 \%$ hemolysis was determined by exposing the erythrocytes to zymosan in the absence of serum.

Neutrophil chemotaxis. C5a activity in mouse serum was evaluated using a C5a-dependent neutrophil migration under agarose assay as described previously (41). Viable human neutrophils (>95\%) were isolated from human blood as described elsewhere (42). Four sets of three equidistant wells were punched into the agarose/gelatin bed of each tissue culture plate with a custom-made hole punch as described elsewhere (41). Mouse serum (20\%) was divided equally into two groups: (a) zymosan-activated (ZAS) or (b) nonactivated. Mouse serum was diluted with gelatin veronal-buffer (0.15 gelatin, $141 \mathrm{mmol} / \mathrm{L} \mathrm{NaCl}, 0.5$ $\mathrm{mmol} / \mathrm{L} \mathrm{MgCl}_{2}, 0.15 \mathrm{mmol} / \mathrm{L} \mathrm{CaCl}_{2}$, and $1.8 \mathrm{mmol} / \mathrm{L}$ sodium barbital $\left[\mathrm{GVB}^{2+}\right]$ ). The chemoattractant (i.e., ZAS or sera) was placed in the inner well and incubated at $37^{\circ} \mathrm{C}$ for 45 minutes. Purified human neutrophils $\left(10^{6} /\right.$ well $)$ were then placed in the middle well, and the vehicle $\left(\mathrm{GVB}^{2+}\right)$ into the outside well. The plates were then incubated at $37^{\circ} \mathrm{C}$ for 2 hours, followed by fixation with $2 \%$ glutaraldehyde overnight. Neutrophil migration was measured with an inverted microscope equipped with an ocular micrometer. The chemotactic index is described as the distance the neutrophils move toward the chemoattractant divided by random migration (i.e., movement toward the vehicle control). All experiments were performed in quadruplicate. The chemotactic index for nonactivated mouse sera for each set of test sera (i.e., anti-C5-treated mice; C6-deficient mice; saline-treat-

Table 1

Severity score of renal tubule damage

\begin{tabular}{lcccc}
\cline { 2 - 4 } Mice & Reperfusion time & Deficient & Sufficient & $P$ value \\
C3 & 48 hours & $1.8 \pm 0.3(n=8)$ & $3.5 \pm 0.2(n=8)$ & 0.0014 \\
C4 & 48 hours & $3.4 \pm 0.3(n=8)$ & $3.5 \pm 0.2(n=8)$ & NS \\
C5 & 48 hours & $1.8 \pm 0.3(n=4)$ & $2.9 \pm 0.2(n=4)$ & 0.0134 \\
C6 & 72 hours & $1.8 \pm 0.2(n=16)$ & $3.4 \pm 0.2(n=16)$ & 0.0001
\end{tabular}

Values shown are means \pm SEM. Numbers in parentheses represent the number of animals studied at each group. $P$ values are for comparisons between deficient and WT control mice. 
Figure 1

Effect of renal ischemia and reperfusion on renal function in C-def and WT mice. Mice underwent renal ischemia for 58 minutes (C3-, C4-, C6-def, and WT mice) or for 40 minutes (C5-def and WT mice). Serum urea nitrogen (BUN) was measured at 6-72 hours after removal of the clamps or sham surgery. (a) C3-def and WT mice; (b) C4-def and WT mice; (c) C5-def and WT mice; (d) C6-def and WT mice; and (e) B6 C3-def and WT mice. Values shown are means \pm SEM. $P$ values are for comparisons between values in deficient and WT mice. Dashed line represents the BUN level in sham-treated mice. ed mice) was subtracted from the ZAS group as described previously (41).

Intraperitoneal neutrophil migration. To determine whether neutrophils can be recruited to sites of inflammation in C6-def mice, thioglycollate, an effective inducer of neutrophil-mediated inflammation was used as described previously (43). C6-def and WT $(\mathrm{CH} 3 / \mathrm{He})$ mice (four mice per group) were injected intraperitoneally with $1 \mathrm{~mL}$ of $3 \%$ thioglycollate in PBS. Control WT mice were injected with PBS. After 3 hours, mice were sacrificed and the peritoneal cavity was washed with $3 \mathrm{~mL}$ of PBS three times. Total cells

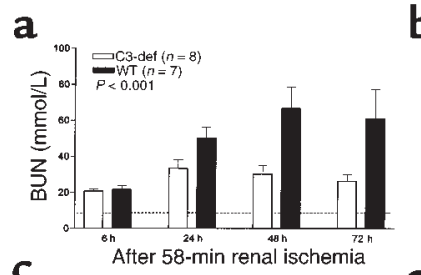

C

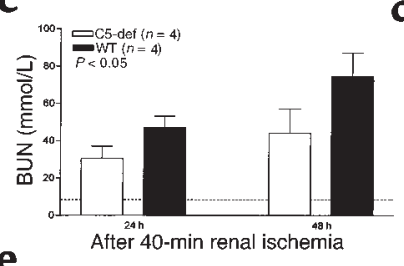

b
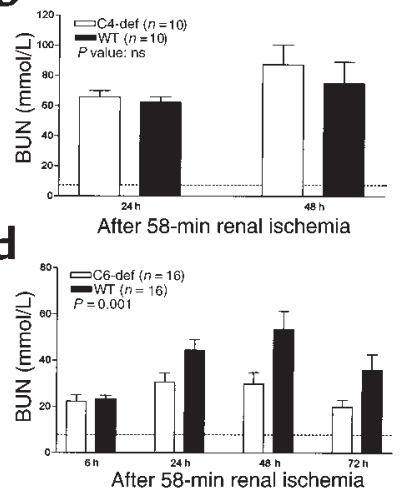

e

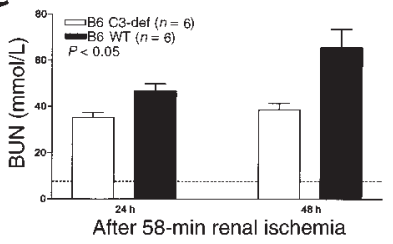

were recovered from the wash by centrifugation at 350 g. Red blood cells were lysed by suspending in $0.5 \mathrm{~mL}$ water for 5 seconds. Isotonicity was restored by adding $30 \mathrm{~mL}$ of PBS. Total numbers of cells were counted using a hemocytometer, and the subpopulations were determined by differential counts on hematoxylinstained smears.

Statistical analysis. All data are presented as mean \pm SEM and subjected to one- and two-factor ANOVA. Individual group values were compared using Student's paired $t$ test. Chemotaxis data were analyzed by one-way ANOVA and Student's $t$ test.

\section{Figure 2}

Effect of renal ischemia and reperfusion on renal morphology in C3-def and WT mice. Light microscopy of kidney corticomedullary junction showing tubular damage at 24,48 , and 72 hours of reperfusion in C3-def mice (a, $\mathbf{c}$, and $\mathbf{e})$ and WT mice (b, d, and $\mathbf{f}) . \times 80$.
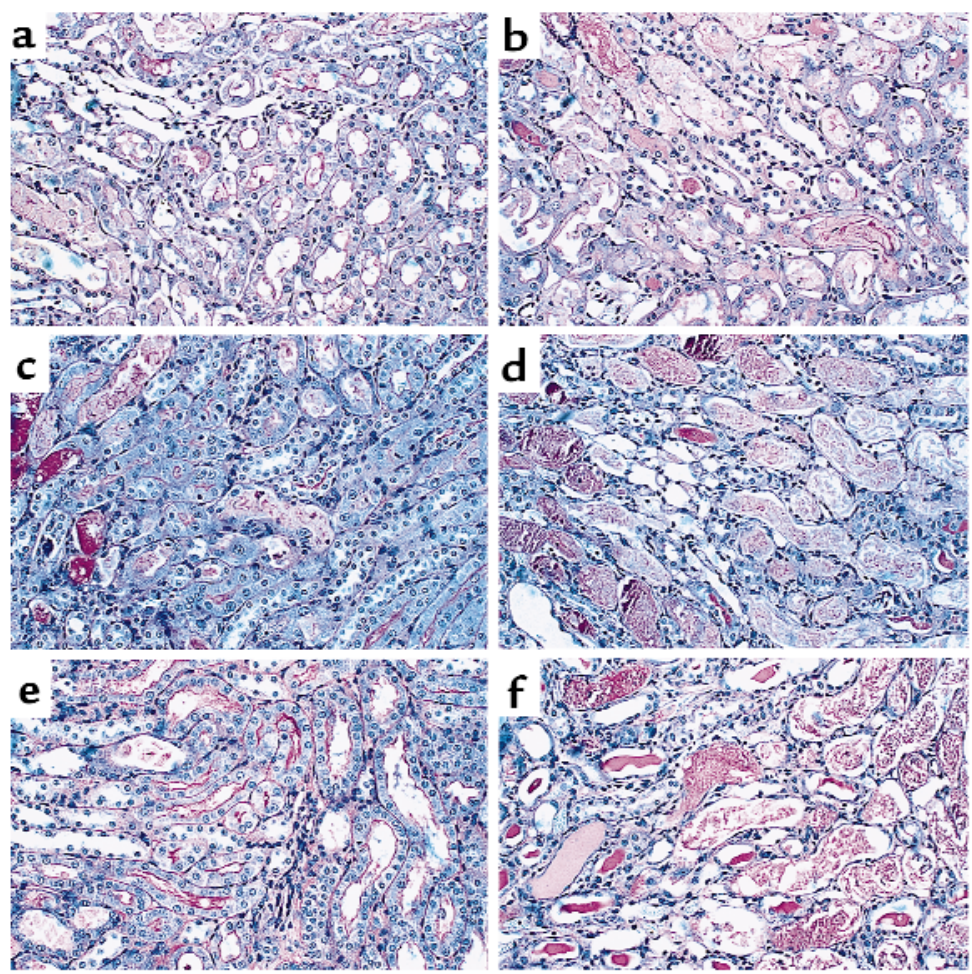


\section{Figure 3}

Effect of renal ischemia and reperfusion on renal morphology in C4-, C5-, and C6-def and WT mice. Light microscopy of kidney corticomedullary junction showing tubular damage at 48 hours of reperfusion in C4$\operatorname{def}(\mathbf{a})$ and WT (b) mice; C5-def (c) and WT (d) mice; and C6-def $(\mathbf{e})$ and WT mice $(\mathbf{f}) . \times 80$.
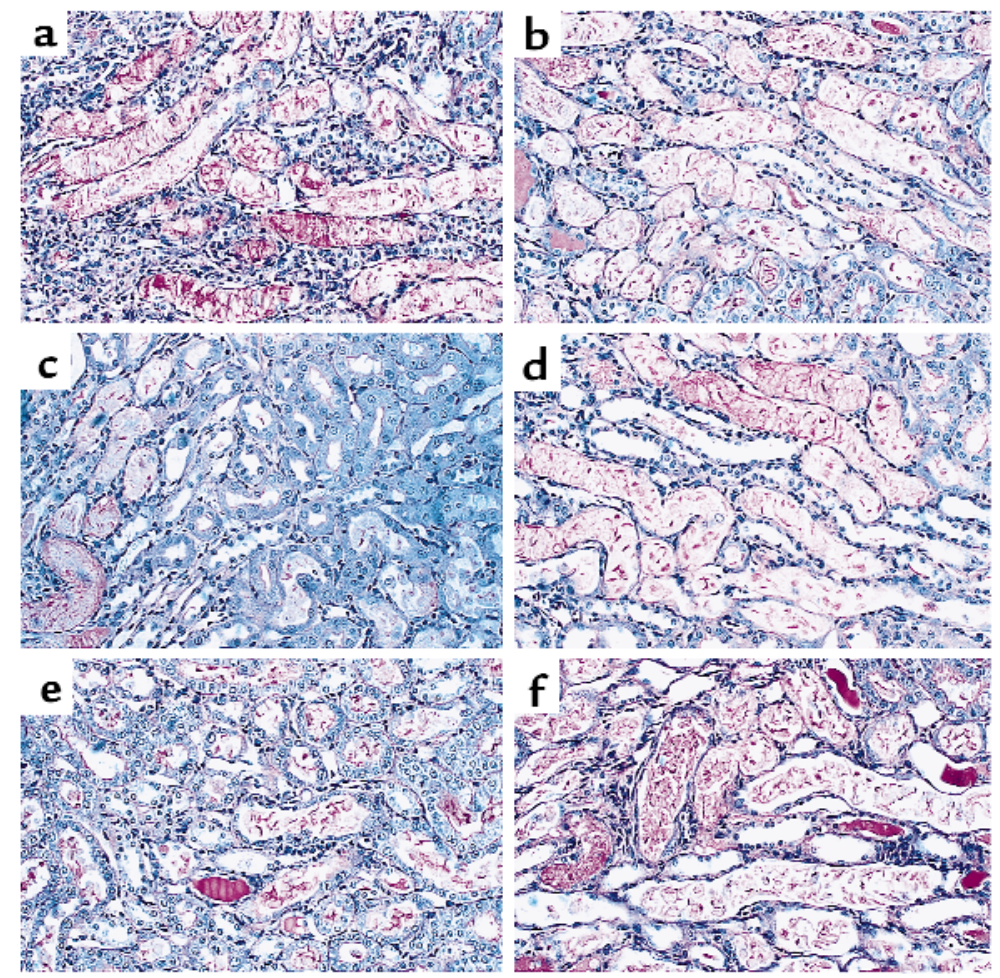

\section{Results}

Renal I/R injury depends on C3 but not C4. As illustrated in Figure 1a, Figure 2, and Table 1, C3-def mice were protected against renal I/ $\mathrm{R}$ injury. The $\mathrm{C} 3$-suf controls in these experiments were $\mathrm{B} 6 \times 129 \mathrm{~F} 2$ mice. The degree of protection was equivalent to $33-55 \%$ reduction of BUN measured 24-72 hours after blood flow was reestablished. In a further experiment, B6-backcrossed C3-def mice were available and were compared directly with B6 C3-suf littermates. Here, C3-def mice showed 45\% reduction in functional injury compared with C3-suf mice (Figure 1e). These data confirm the previous experiment and indicate that the difference in susceptibility to injury was due to $\mathrm{C} 3$, rather than minor differences in genetic background. Morphological damage was evident in ischemic kidney as early as 2 hours after the commencement of reperfusion, but the difference in structural and functional injury between C3-def and -suf mice was only appreciable by 24 hours (Figure 1a).

Because $\mathrm{C} 3$ plays a role in both the classic and alternative pathways of $\mathrm{C}$ activation, to distinguish possible classic pathway involvement, we examined I/R injury in C4-def mice. As can be seen in Figure 1b; Figure 3, a and $\mathrm{b}$; and Table 1, structural and functional injury at 24 and 48 hours of reperfusion was not significantly different between C4-def and WT mice. These results indicate that classic pathway mediation did not apply in this model.

The terminal components of complement mediate renal $I / R$ injury. To delineate the role of C5 (which is activated downstream of C3) we performed I/R experiments in C5def mice and congenic (B10D2) controls. B10D2 mice proved more sensitive to ischemia than $\mathrm{B} 6$ mice. For this reason, we used a reduced ischemic time (40 minutes), adjusted to give comparable functional and structural impairment with that in $\mathrm{B} 6$ mice subjected to 58-minute ischemia (data not shown). Under these conditions, the functional injury in C5-def mice was reduced by $35-40 \%$ of the level in WT B10D2 mice (Figure 1c). Renal tubular damage was reduced as shown in Figure 2, c and d, and Table 1 . These results suggest a substantial role for $\mathrm{C} 5$ in the generation of renal I/R injury.

Because C5 is cleaved into C5a and C5b, the experiments in C5-def mice do not distinguish between the possibility of an effect of C5a and an effect of C5b-9 (in which $\mathrm{C} 5 \mathrm{~b}$ is a participant). To help dissect these effector functions of $\mathrm{C5}$, we performed ischemic studies in C6-def mice. These mice are able to generate C5a but cannot form C5b-9. Compared with C6-suf controls, C6-def mice exhibited significant sparing of morphological and functional injury. The BUN was reduced by $31-55 \%$, as reflected in Figure 1d. The tubular damage was reduced by $47 \%$ (Table 1). The histological pattern of injury was indistinguishable in the WT controls for

\section{Table 2}

MPO activity in mouse kidney

Units of MPO activity per milligram, OD $460 \mathrm{~nm}$

$\begin{array}{lcccc}\text { Mice Reperfusion time } & \text { Deficient } & \text { Sufficient } & P \text { value } \\ \text { C3 } & 24 \text { hours } & 1.92 \pm 0.29(n=6) & 3.23 \pm 0.36(n=6) & 0.017 \\ \text { C6 } & 24 \text { hours } & 2.3 \pm 0.29(n=8) & 3.644 \pm 0.46(n=8) & 0.0334 \\ \text { C3 } & \text { Sham control } & 0.78 \pm 0.01(n=4) & 0.70 \pm 0.01(n=4) & \text { NS } \\ \text { C6 } & \text { Sham control } & 0.75 \pm 0.01(n=4) & 0.80 \pm 0.01(n=4) & \text { NS }\end{array}$

Values shown are means \pm SEM. Numbers in parentheses represent the number of animals studied at each group. $P$ values are for comparisons between deficient and WT control mice. 
$\mathbf{a}$

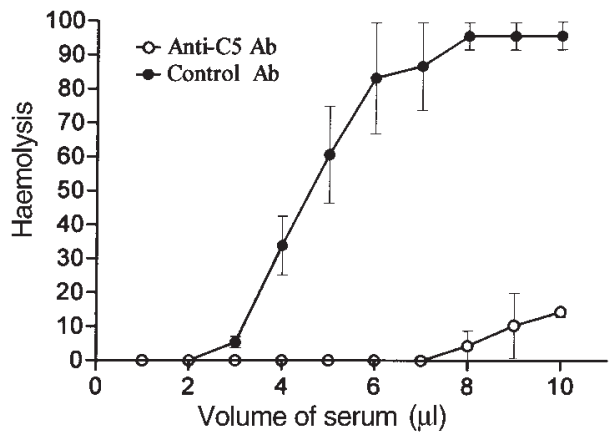

b

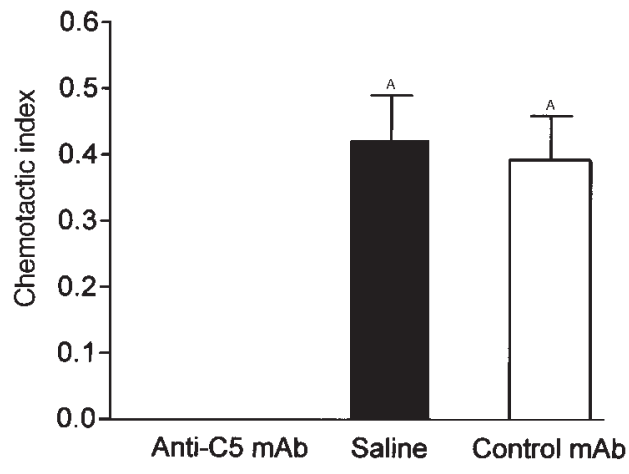

Figure 4

Inhibition of mouse $\mathrm{C}$ activity by anti-C5 mAb. WT C3H/He mice received a single intraperitoneal injection of anti-C5 (BB5.1) or control (135.1) $\mathrm{mAb}(50 \mathrm{mg} / \mathrm{kg}), 16$ hours before induction of renal ischemia. Sera were collected for analysis at 72 hours of reperfusion. (a) Hemolytic assay. Values shown are means \pm SEM of triplicate determination for each of three mice. (b) Chemotactic assay. Anti-C5 mAb inhibited ZAS-induced neutrophil chemotaxis under agarose versus control mAb. Chemotactic index of nonactivated mouse serum was subtracted from the chemotactic index of ZAS in each treatment group to normalize data. Values shown are means $\pm S E M$. ${ }^{A} P<0.05$ versus anti-C5 mAb treated sera.

the C3-def mice and the C6-def mice (Figures $2 \mathrm{~d}$ and $3 f)$. These data provide evidence for the participation of $\mathrm{C} 6$ and strongly implicate the involvement of the MAC (C5b-9) in renal I/R injury.

To evaluate further the role of $\mathrm{C} 5 \mathrm{a}$ in the C6-def mice, we blocked the formation of $\mathrm{C} 5 \mathrm{a}$ using $\mathrm{mAb}$. As can be seen in Figure 4, treatment of WT $(\mathrm{C} 3 \mathrm{H} / \mathrm{He})$ mice with BB5.1 inhibited both complement hemolytic activity (Figure 4a) and chemotactic activity (Figure 4b) mediated by C5b-9 and C5a, respectively. Despite the ability of BB5.1 to block C5a activity, C6-def mice pretreated with BB5.1 failed to prevent the injury further, compared with control antibody 135.8 treatment. This is illustrated in Figure 5.

C6-def mice were derived from a mutant strain later backcrossed with $\mathrm{C} 3 \mathrm{H} / \mathrm{He}$. To verify that the protection afforded in these mice was due to $\mathrm{C} 6$ deficiency rather than another undefined difference, we reconstituted the C6-def mice with C6. Preliminary tests in duplicate mice showed that a single intraperitoneal injection of C6 (75 $\mu \mathrm{g} /$ mouse) restored serum complement hemolytic activity to $20 \%$ of the WT value $(\mathrm{C} 3 \mathrm{H} / \mathrm{He})$, which peaked 16 hours after dose (data not shown). For ischemic study, C6-def mice were treated with $\mathrm{C} 6$ before and after the ischemic period. C6reconstituted mice displayed similar sensitivity to the renal injury as did the WT mice (Figure 6). The histological injury in the reconstituted mice WT mice was indistinguishable (data not shown). These results establish that resistance to I/R injury in the mutant strain was due to deficiency of C6.

Morphological injury of the tubule is a direct consequence of complement. Tubular injury (tubule thinning, dilatation, loss of proximal brush border, protein casts) was maximal in the area of the corticomedullary junction (Figures 2 and 3). This corresponded to an area of uniform complement deposition on the basolateral tubular surface in WT mice (cf. Figure 7b with 7a). Large and small blood vessels were normal in appearance and only occasionally stained for complement. Staining for fibrin both with specific antibody (data not shown) and MSB (Figure 7, c and d) showed no vascular abnormality, in particular no evidence of thrombosis in any mouse.

Neutrophil infiltration was maximal in the corticomedullary region corresponding to the area of severe injury and complement deposit. Histological infiltration was reduced in C3-def mice (cf. Figure 7e with 7f) together with reduction in neutrophil MPO activity by $41 \%$ at 24 hours (Table 2). Interestingly, C6-def mice showed significant decline in neutrophil activity, by $37 \%$ at 24 hours (Table 2), despite the ability of C6-def mice to generate anaphylatoxins C3a and C5a. Furthermore, blockade of C5a formation in C6-def mice did not lead to additional reduction of MPO activity, compared with control antibody-treated C6-def mice ( $2.10 \pm 0.33$ vs. $2.17 \pm 0.42$ units of MPO activity per milligram of protein). To exclude an

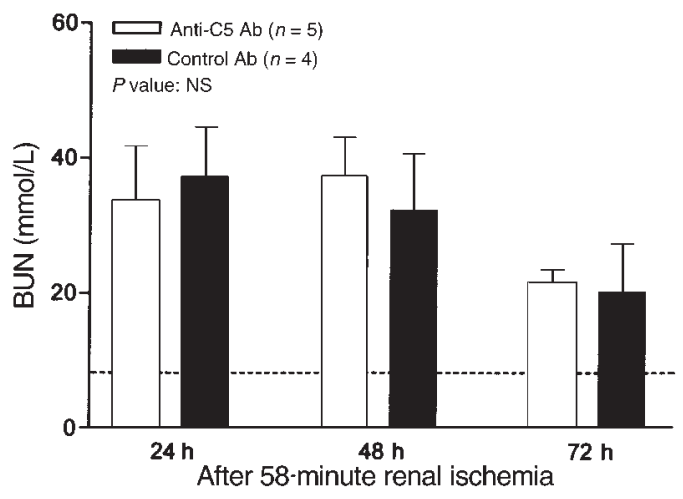

Figure 5

Effects of anti-C5 mAb on I/R injury in C6-def mice. C6-def mice received an injection of anti-C5 or control mAb $(50 \mathrm{mg} / \mathrm{kg}) 16$ hours before induction of renal ischemia. BUN was measured at 24,48 , and 72 hours of reperfusion or after sham surgery. Values shown are means \pm SEM. $P$ values are shown for comparisons between values in deficient and WT mice. Dashed line represents the BUN level in sham-treated mice. 
Figure 6

Reconstitution of C6-def mice with C6 and its effect on I/R injury. C6-def mice received two injections of purified C6 ( $75 \mu \mathrm{g} /$ mouse) at 16 hours before and 1 hour after the period of ischemia. BUN was measured at 24 and 48 hours of reperfusion. Values shown are means \pm SEM. Numbers in parentheses represent the number of animals studied at each group. $P$ values are for comparisons between C6-def and restored mice and WT controls. Dashed line represents the BUN level in sham mice.

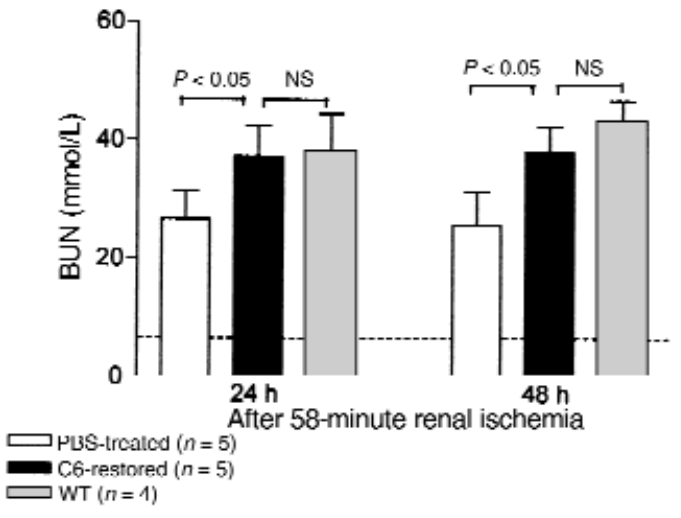

intrinsic neutrophil defect in the C6-def mice, the capacity for neutrophil migration was evaluated. Intraperitoneal injection of thioglycollate induced a neutrophil response in C6-def mice that was no different from WT C3H/He (total cell counts in the peritoneal washout $4.6 \times 10^{6} \pm 0.33$ vs. $4.1 \times 10^{6} \pm 0.35$, of which $87.5 \%$ and $85.4 \%$ were neutrophils, respectively). These data argue against a strong role for $\mathrm{C} 5 \mathrm{a} /$ neutrophil-mediated injury in this model and imply that neutrophil recruitment is partly a consequence of MAC-mediated damage.

\section{Discussion}

This study set out to examine the role of $\mathrm{C}$ in the genesis of renal I/R injury, in particular to determine the relative importance of the early (C3, C4), intermediate (C5), and late (C6) components of the C cascade. Structural and functional injury was reduced by about onehalf in C-def mice, in accord with the results of studies of other organs in laboratory animals with early C pathway deficiency or depletion (23-26). More emphatically, our results show that mice with isolated deficiency of terminal pathway activation (C6) exhibited a similar degree of protection to those with more proximal interruption of the complement cascade (C3). These results provide compelling evidence that MAC (to which C6 contributes) is a critical effector mechanism through which $\mathrm{C}$ mediates renal postischemic injury.

Furthermore, the C6-def mice treated with anti-C5 antibody gain no further protection against I/R injury. Cleavage of $\mathrm{C} 5$ by the classic or alternative pathway generates C5a and C5b. C5a is a biologically active peptide that engages receptor on neutrophils and other inflammatory cells (44-46). C5b is the first component to participate in the assembly of C5b-9, the MAC. C6-def animals are thus unable to generate functional MAC but can form C5a. Preventing C5a formation in mice in which MAC was disabled lead to no further benefit, as it neither improved renal function nor reduced inflam-

\section{Figure 7}

Staining for product of complement activation, neutrophils, and fibrin on kidney tissue. C3-def and WT mice were induced with 58-minute renal ischemia followed by 24-hour reperfusion. (a and b) Immunochemical staining of C $3 \mathrm{~d}$ at kidney corticomedullary junction in C3-def (a) and WT (b) mice. Arrows point to the deposition of $\mathrm{C} 3 \mathrm{~d}$ on the basolateral surface of renal tubular epithelium; asterisks show locations of peritubular capillaries. $\times 128$. ( $\mathbf{c}$ and $\mathbf{d})$ MSB staining at damaged tubular area in C3-def (c) and WT (d) mice. $\times 80$. Nuclei, erythrocytes, fibrin, and connective tissue should be stained as black, yellow, red, and blue, respectively. Necrotic tissue tubular epithelial cells are stained gray-blue (d). Arrows point at peritubular capillaries showing no fibrin formation. (e and $\mathbf{f}$ ) Immunochemical staining of neutrophils at kidney corticomedullary junction in C3$\operatorname{def}(\mathbf{e})$ and WT $(\mathbf{f})$ mice. $\times 50$.

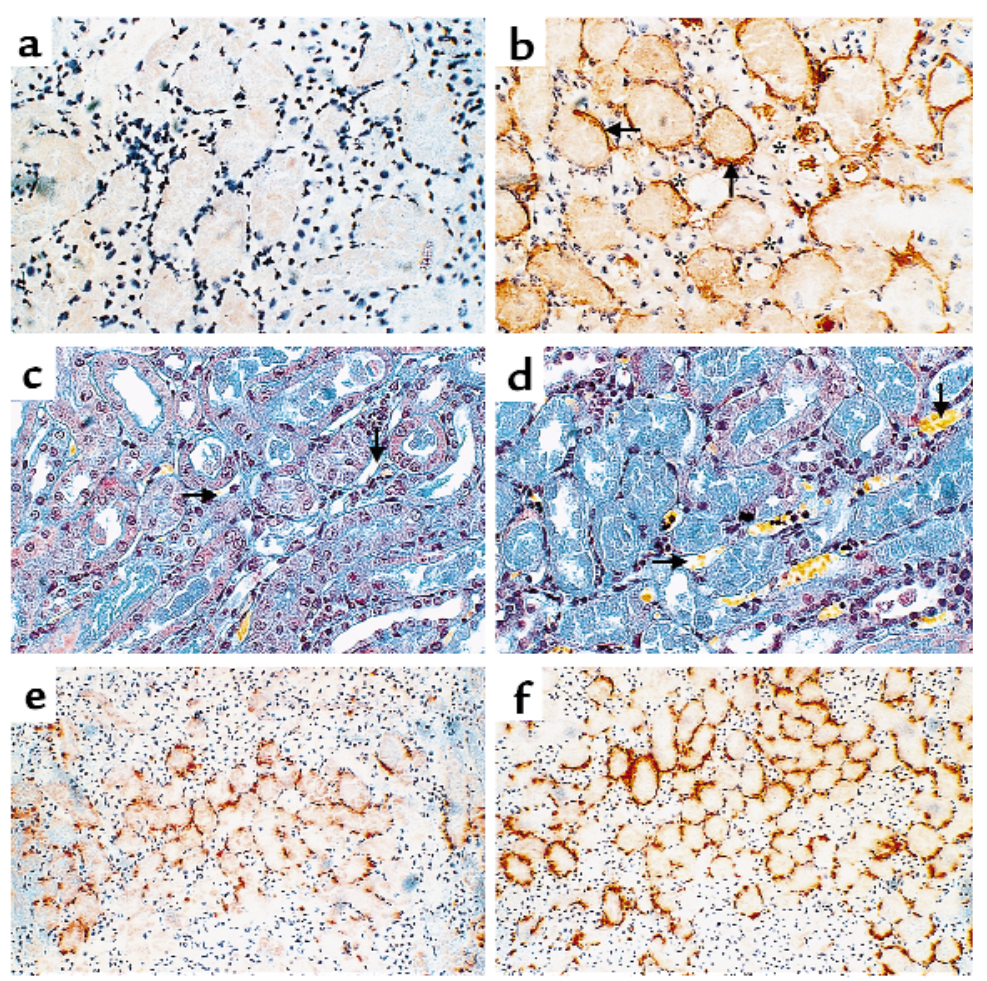


matory cell infiltration. Our data therefore do not support a model of renal I/R injury in which $\mathrm{C} 5 \mathrm{a} /$ neutrophil mediation plays a key role. This is in contrast to heart, intestine, and lung, in which therapeutic C5a blockade led to significant prevention of I/R injury (47-49).

According to our results, the resistance shown by $\mathrm{C5}$ def mice to renal I/R injury was probably due to the inability to generate $\mathrm{C} 5 \mathrm{~b}$, rather than $\mathrm{C} 5 \mathrm{a}$. A key role for $\mathrm{C} 5$ also applies in rat myocardial I/R injury, in which administration of anti-C5 antibody lead to significant reduction of injury (50). However, a limitation in that study, as in the present study of C5-def mice, is that it was unable to distinguish between the possible effects of $\mathrm{C} 5 \mathrm{a}$ and MAC, as both routes are defective without C5. Our results in the C6-def mice, however, resolve this issue and clearly emphasize the role of MAC in renal I/R.

Tissue injury in the present model was independent of $\mathrm{C} 4$, tending to discount a role for classic pathway activation. However, other studies have shown that hypoxia can activate the classic as well as alternative pathways $(51,52)$. Moreover, classic pathway activation contributes to ischemic damage in mouse muscle and intestine $(26,48)$. We cannot account for the discrepancy, except to suggest that it may be due to organ-specific differences in anatomy or physiology. For example, human proximal tubular epithelial cells have deficient expression of the $\mathrm{C}$ regulatory proteins CD55 and CD46 (53) and can activate the alternative pathway spontaneously at low concentrations of serum (28). We have confirmed this observation in cultured mouse and human tubular epithelial cells using 5-20\% normal serum (unpublished data). In contrast, human endothelial cells are reported not to show spontaneous activation of complement at this concentration (17), possibly due to differences in the cellular content of proteases that can cleave $\mathrm{C} 3$, or in the level of expression of membrane-bound C inhibitors (28).

In addition, the outer medullary zone of the kidney is very vulnerable to decrease in blood flow, especially the S3 segment of proximal tubule (54). The containment of injury at the corticomedullary area was characteristic of this model. It is possible that the release of proteases by proximal tubules in the area of hypoxia rapidly triggers complement activation by its alternative pathway. Together these factors could have favored alternative pathway activation in the present study. Thus, renal I/R injury is alternative pathway dependent, whereas muscle $\mathrm{I} / \mathrm{R}$ injury is classic pathway dependent. It will be important to establish the significance of this finding by examination of a wider range of organs.

Another conspicuous feature of this model was the apparent lack of endothelial involvement, at least with histological and immunochemical analysis. This sparing of the vessel wall from $\mathrm{C}$ attack is distinct from the case with rat myocardial I/R injury, for example. Here, diffuse, small vessel endothelial swelling and thrombosis accompanied by $\mathrm{C}$ deposition and neutrophil infiltration was substantially prevented by $\mathrm{C}$ inhibition (23). This led to marked reduction in distal tissue infarction (23). Hence, $\mathrm{C}$ attack in renal I/R injury is based on the renal parenchyma, and in myocardial reperfusion, injury involves both acute endothelial injury as well distal parenchymal injury. Our results do not exclude more subtle changes in the endothelium enabling neutrophil recruitment. However, the absence of overt vascular injury or evidence of $\mathrm{C}$ attack suggest a different underlying process mechanism of $\mathrm{C}$ attack in renal I/R injury. It remains possible that the distribution of $\mathrm{C}$ inhibitors in different tissue compartments is a key factor in renal injury, as renal vessels are relatively well endowed with membrane-bound inhibitors such CD46 and CD55 (53).

Taken together these findings suggest that MAC alone may account for the contribution of complement to injury of the hypoxia-sensitive deep renal tubule, independently of vascular damage or C5a-mediated neutrophil infiltration. Renal I/R injury differs from that in other organ models, in which vascular damage and C5amediated injury play prominent roles. Other studies have clearly established that neutrophils are key participants in the development of $\mathrm{I} / \mathrm{R}(55,56)$. The data here do not discount a role for neutrophils, but imply that their involvement is largely through a means distinct from C5a. Moreover, the results in this study with C6-def mice suggest that either MAC itself (57) or resulting tissue damage is a stimulant to neutrophil recruitment. This notion is reinforced by the finding that the degree of infiltration in C3def mice is no less than that in C6-def mice, which cannot generate either $\mathrm{C} 3 \mathrm{a}$ or $\mathrm{C} 5 \mathrm{a}$. This tends to minimize the importance of C3a as well as C5a in this model.

The use of multiple-paired WT and deficient strains allowed us to tease out the effective components of $\mathrm{C}$. The approach combining $\mathrm{C}$ deficiency with depletion allowed us to pare away at the function of individual components in the same genetic background. The results here, alongside the results of other studies using C inhibitors $(23,24,50)$, suggest that therapeutic intervention at the level of the terminal pathway could significantly alter the extent of ischemic damage. Intervention at this level of the $\mathrm{C}$ cascade would avoid interfering with the antimicrobial functions of the early components ( $\mathrm{C} 3 \mathrm{a}$ and $\mathrm{C} 5 \mathrm{a}$ ) and, in addition, would preserve the immunomodulatory functions of $\mathrm{C} 3 \mathrm{~b}$ and $\mathrm{C} 3 \mathrm{~d}$, which might be compromised in more proximal blockade of the $\mathrm{C}$ cascade.

\section{Acknowledgments}

This study was funded by The Wellcome Trust (ref: 054931) of the United Kingdom. We thank D.J. Hearse for valuable advice. We thank P. Lachmann for kindly providing the C6-def mice. We thank P.B. Morgan for kindly providing the purified C6. We thank B. Hartley for scrutinizing the histological sections, C. Turner for creatinine measurement, and $\mathrm{K}$. Whoolery for the chemotaxis assays. We are grateful to M. Carroll for providing the $\mathrm{C} 3$ - and $\mathrm{C} 4-\mathrm{kn}$ ockout mice.

\footnotetext{
1. Hearse, D.J., and Bolli, R. 1992. Reperfusion induced injury: manifestations, mechanisms, and clinical relevance. Cardiovasc. Res. 26:101-108.

2. Thadhani, R., Pascual, M., and Bonventre, J.V. 1996. Acute renal failure. N. Engl. J. Med. 334:1448-1460.
} 
3. Bonventre, J.V. 1993. Mechanisms of ischemic acute renal failure. Kidney Int. 43:1160-1178.

4. Troppmann, C., et al. 1995. Delayed graft function, acute rejection, and outcome after cadaver renal transplantation. The multivariate analysis. Transplantation. 59:962-968.

5. Pagtalunan, M.E., Olson, J.L., Tilney, N.L., and Meyer, T.W. 1999. Late consequences of acute ischemic injury to a solitary kidney. J. Am. Soc. Nephrol. 10:366-373.

6. Korthuis, R.J., Smith, J.K., and Carden, D.L. 1989. Hypoxic reperfusion attenuates postischemic microvascular injury. Am. J. Physiol. 256:H315-H319.

7. Williams, F.M. 1996. Neutrophils and myocardial reperfusion injury. Pharmacol. Ther. 72:1-12.

8. Kilgore, K.S., Friedrichs, G.S., Homeister, J.W., and Lucchesi, B.R. 1994 The complement system in myocardial ischaemia/reperfusion injury. Cardiovasc. Res. 28:437-444.

9. Kelly, K.J., et al. 1996. Intercellular adhesion molecule-1-deficient mice are protected against ischemic renal injury. J. Clin. Invest. 97:1056-1063.

10. Daemen, M.A., van't Veer, C., Wolfs, T.G., and Buurman, W.A. 1999. Ischemia/reperfusion-induced IFN-gamma up-regulation: involvement of IL-12 and IL-18. J. Immunol. 162:5506-5510.

11. Rabb, H., O’Meara, Y.M., Maderna, P., Coleman, P., and Brady, H.R. 1997. Leukocytes, cell adhesion molecules and ischemic acute renal failure. Kidney Int. 51:1463-1468.

12. Takada, M., Chandraker, A., Nadeau, K.C., Sayegh, M.H., and Tilney, N. 1998. The role of the B7 costimulatory pathway in experimental cold ischemia/reperfusion injury. J. Clin. Invest. 100:1199-1203.

13. Hugli, T.E. 1983. The chemistry and biology of C3a, C4a and C5a and their effects on cells. In Biological response mediators and modulators. J.T. August, editor. Academic Press. New York, New York, USA. 99-116.

14. del Balzo, U.H., Levi, R., and Polley, M.J. 1985. Cardiac dysfunction caused by purified human C3a anaphylatoxin. Proc. Natl. Acad. Sci. USA. 82:886-890.

15. Tonnesen, M.G., et al. 1989. Adherence of neutrophils to cultured human microvascular endothelial cells. Stimulation by chemotactic peptides and lipid mediators and dependence upon the Mac-1, LFA-1, p150,95 glycoprotein family. J. Clin. Invest. 83:637-646.

16. Foreman, K.E., Glovsky, M.M., Warner, R.L., Horvath, S.J., and Ward, P.A. 1996. Comparative effect of C3a and C5a on adhesion molecule expression on neutrophils and endothelial cells. Inflammation. 20:1-9.

17. Biancone, L., et al. 1994. Alternative pathway activation of complement by cultured human proximal tubular epithelial cells. Kidney Int. 45:451-460.

18. Kilgore, K.S., et al. 1997. Sublytic concentrations of the membrane attack complex of complement induce endothelial interleukin- 8 and monocyte chemoattractant protein-1 through nuclear factor-kappa B activation. Am. J. Pathol. 150:2019-2031.

19. Hansch, G.M., Seitz, M., and Betz, M. 1987. Effect of the late complement components C5b-9 on human monocytes: release of prostanoids, oxygen radicals and of a factor inducing cell proliferation. Int. Arch. Allergy Immunol. 82:317-320

20. Seeger, W., Suttorp, N., Hellwig, A., and Bhakdi, S. 1986. Noncytolytic terminal complement complexes may serve as calcium gates to elicit leukotriene B4 generation in human polymorphonuclear leukocytes. $J$. Immunol. 137:1286-1293.

21. Campbell, A.K., and Morgan, B.P. 1985. Monoclonal antibodies demonstrate protection of polymorphonuclear leukocytes against complemen attack. Nature. 317:164-166.

22. Wiedmer, T., Esmon, C.T., and Sims, P.J. 1986. Complement proteins C5b-9 stimulate procoagulant activity through platelet prothrombinase. Blood. 68:875-880.

23. Weisman, H.F., et al. 1990. Soluble human complement receptor type 1: in vivo inhibitor of complement suppressing post-ischemic myocardial inflammation and necrosis. Science. 249:146-151.

24. Ikai, M., et al. 1996. Complement plays an essential role in shock following intestinal ischaemia in rats. Clin. Exp. Immunol. 106:156-159.

25. Eppinger, M.J., Deeb, G.M., Bolling, S.F., and Ward, P.A. 1997. Mediators of ischemia-reperfusion injury of rat lung. Am. J. Pathol. 150:1773-1784.

26. Weiser, M.R., et al. 1996. Reperfusion injury of ischemic skeletal muscle is mediated by natural antibody and complement. J. Exp. Med. 183:2343-2348.

27. Jones, S.G., Morrisey, K., Williams, J.D., and Phillips, A.O. 1999. TGFbeta1 stimulates the release of pre-formed bFGF from renal proximal tubular cells. Kidney Int. 56:83-91.

28. David, S., et al. 1997. Alternative pathway complement activation induces proinflammatory activity in human proximal tubular epithelial cells. Nephrol. Dial. Transplant. 12:51-56.

29. Burton, C.J., Combe, C., Walls, J., and Harris, K.P. 1996. Fibronectin production by human tubular cells: the effect of apical protein. Kidney Int 50:760-767.

30. Deckers, J.G., et al. 1998. IL-4 and IL-13 augment cytokine- and CD40- induced RANTES production by human renal tubular epithelial cells in vitro. J. Am. Soc. Nephrol. 9:1187-1193.

31. Hearse, D.J., Maxwell, L., Saldanha, C., and Gavin, J.B. 1993. The myocardial vasculature during ischemia and reperfusion: a target for injury and protection. J. Mol. Cell. Cardiol. 25:759-800.

32. Wessels, M.R., et al. 1995. Studies of group B streptococcal infection in mice deficient in complement component $\mathrm{C} 3$ or $\mathrm{C} 4$ demonstrate an essential role for complement in both innate and acquired immunity. Proc. Natl. Acad. Sci. USA. 92:11490-11494.

33. Fischer, M.B., et al. 1996. Regulation of the B cell response to T-dependent antigens by classical pathway complement. J. Immunol. 157:549-556.

34. Orren, A., Wallance, M.E., Horbart, M.J., and Lachmann, P.J. 1989. C6 polymorphism and C6 deficiency in site strains of the mutation-prone Peru-Coppock mice. Complement Inflamm. 6:295-296. (Abstr.)

35. Rabb, H., et al. 1996. Renal ischemic-reperfusion injury in L-selectin-deficient mice. Am. J. Physiol. 271:F408-F413.

36. Drury, R.A.B., and Wallington, E.A. 1980. Carleton's histological technique. Oxford University Press. Oxford, United Kingdom. 228-229.

37. Hillegass, L.M., Griswold, D.E., Brickson, B., and Albrightson-Winslow, C. 1990 . Assessment of myeloperoxidase activity in whole rat kidney. J. Pharmacol. Methods. 24:285-295.

38. Wang, Y., Rollins, S.A., Madri, J.A., and Matis, L.A. 1995. Anti-C5 monoclonal antibody therapy prevents collagen-induced arthritis and ameliorates established disease. Proc. Natl. Acad. Sci. USA. 92:8955-8959.

39. Timmerman, J.J., et al. 1997. Complement C6 and C2 biosynthesis in syngeneic PVG/c- and PVG/c+ rat strains. Scand. J. Immunol. 46:366-372.

40. Klerx, J.P., Beukelman, C.J., Van Dijk, H., and Willers, J.M. 1983. Microassay for colorimetric estimation of complement activity in guinea pig, human and mouse serum. J. Immunol. Methods. 63:215-220.

41. Vakeva, A.P., et al. 1998. Myocardial infarction and apoptosis after myocardial ischemia and reperfusion: role of the terminal complement components and inhibition by anti-C5 therapy. Circulation. 97:2259-2267.

42. Colgan, S.P., Dzus, A.L., and Parkos, C.A. 1996. Epithelial exposure to hypoxia modulates neutrophil transepithelial migration. J. Exp. Med. 184:1003-1015.

43. Mayadas, T.N., Johnson, R.C., Rayburn, H., Hynes, R.O., and Wagner, D.D. 1993. Leukocyte rolling and extravasation are severely compromised in P selectin-deficient mice. Cell. 74:541-554.

44. Sengelov, H. 1995. Complement receptors in neutrophils. Crit. Rev. Immunol. 15:107-131.

45. Wetsel, R.A. 1995. Expression of the complement C5a anaphylatoxin receptor (C5aR) on non-myeloid cells. Immunol. Lett. 44:183-187.

46. Nataf, S., Davoust, N., Ames, R.S., and Barnum, S.R. 1999. Human T cells express the C5a receptor and are chemoattracted to C5a. J. Immunol. 162:4018-4023.

47. Tofukuji, M., et al. 1998. Anti-c5a monoclonal antibody reduces cardiopulmonary bypass and cardioplegia-induced coronary endothelial dysfunction. J. Thorac. Cardiovasc. Surg. 116:1060-1068.

48. Williams, J.P., et al. 1999. Intestinal reperfusion injury is mediated by IgM and complement. J. Appl. Physiol. 86:938-942.

49. Heller, T., et al. 1999. Selection of a C5a receptor antagonist from phage libraries attenuating the inflammatory response in immune complex disease and ischemia/reperfusion injury. J. Immunol. 163:985-994.

50. Vakeva, A.P., et al. 1998. Myocardial infarction and apoptosis after myocardial ischemia and reperfusion: role of the terminal complement components and inhibition by anti-C5 therapy. Circulation. 97:2259-2267.

51. Pemberton, M., Anderson, G., Vetvicka, V., Justus, D.E., and Ross, G.D. 1993. Microvascular effects of complement blockade with soluble recombinant CR1 on ischemia/reperfusion injury of skeletal muscle. J. Immunol. 150:5104-5113.

52. Murohara, T., Guo, J.P., Delyani, J.A., and Lefer, A.M. 1995. Cardioprotective effects of selective inhibition of the two complement activation pathways in myocardial ischemia and reperfusion injury. Methods Find. Exp. Clin. Pharmacol. 17:499-507.

53. Ichida, S., Yuzawa, Y., Okada, H., Yoshioka, K., and Matsuo, S. 1994. Localization of the complement regulatory proteins in the normal human kidney. Kidney Int. 46:89-96.

54. Kashgarian, M. 1998. Acute tubular necrosis and ischemic renal injury. In Heptinstall's pathology of the kidney. J.C. Jennett, J.L. Olson, M.M. Schwartz, and F.G. Silva, editors. Lippincott-Raven Publishers. New York, New York, USA/Philadelphia, Pennsylvania, USA. 863-890.

55. Litt, M.R., et al. 1989. Neutrophil depletion limited to reperfusion reduces myocardial infarct size after 90 minutes of ischemia. Evidence for neutrophil-mediated reperfusion injury. Circulation. 80:1816-1827.

56. Vitola, J.V., Forman, M.B., Holsinger, J.P., Atkinson, J.B., and Murray, J.J. 1997. Reduction of myocardial infarct size in rabbits and inhibition of activation of rabbit and human neutrophils by lidocaine. Am. Heart J. 133:315-322.

57. Wang, C., et al. 1995. Hemolytically inactive C5b67 complex: an agonist of polymorphonuclear leukocytes. Blood. 85:2570-2578. 